
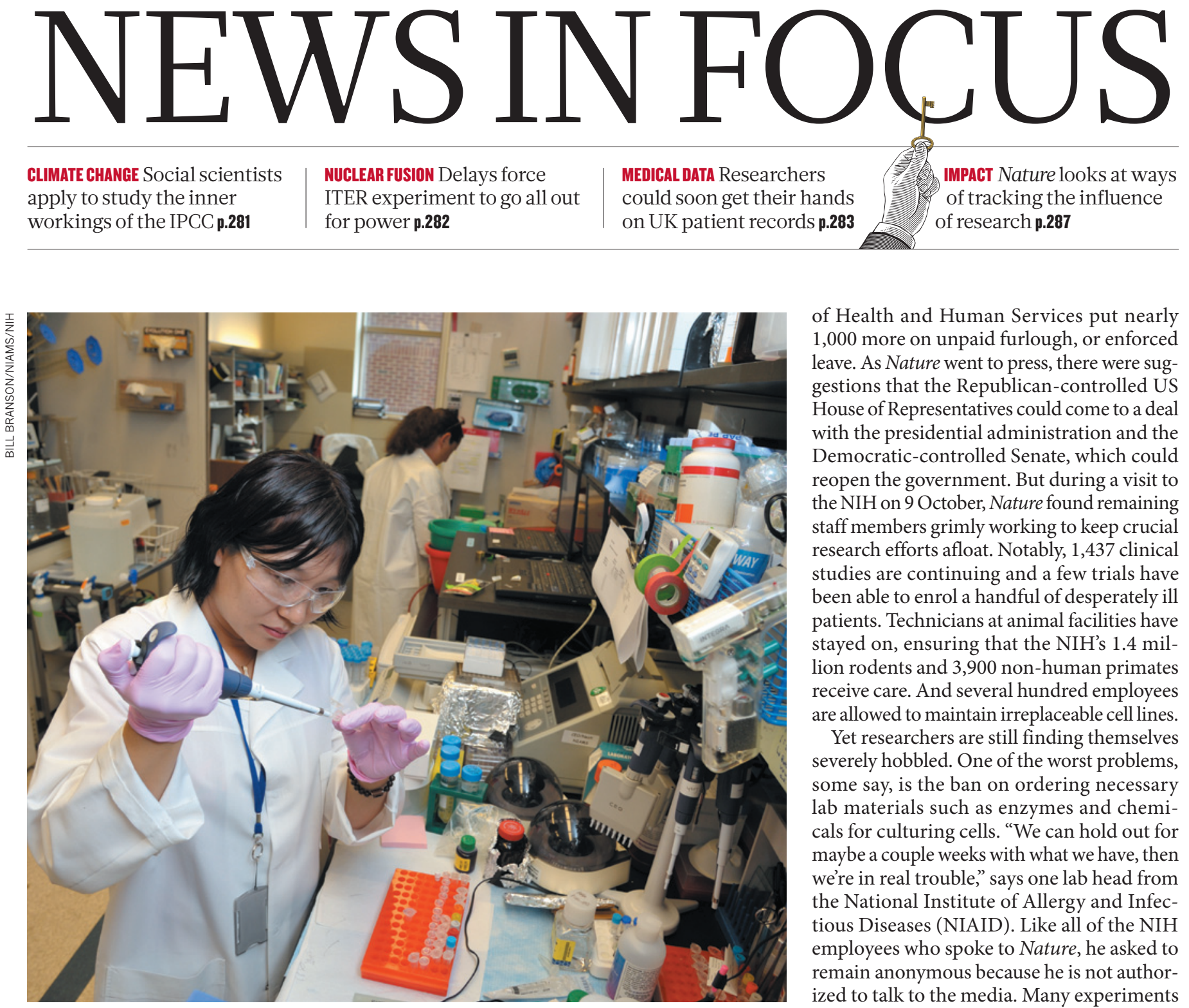

A skeleton staff at the US National Institutes of Health has struggled to keep experiments afloat. GOVERNMENT

\title{
NIH campus endures slow decay
}

\section{Experiments suffer from lack of lab materials and staff during US government shutdown.}

\section{BY SARA REARDON}

$\mathrm{B}$ leak grey skies mirror the mood of the skeleton staff trickling through the gates of the main US National Institutes of Health campus in Bethesda, Maryland. Most of the principal investigators are absent: without students to advise or meetings to attend, there is little point in being there. Perhaps one out of every ten windows is lit up, revealing lonely postdocs working on what few experiments they are allowed to maintain as the US government shutdown drags on.

On 1 October, after federal budget negotiations reached an impasse and forced the shutdown, the NIH sent $73 \%$ of its 18,646 employees home. During the second week of the shutdown, the US Department of Health and Human Services put nearly 1,000 more on unpaid furlough, or enforced leave. As Nature went to press, there were suggestions that the Republican-controlled US House of Representatives could come to a deal with the presidential administration and the Democratic-controlled Senate, which could reopen the government. But during a visit to the NIH on 9 October, Nature found remaining staff members grimly working to keep crucial research efforts afloat. Notably, 1,437 clinical studies are continuing and a few trials have been able to enrol a handful of desperately ill patients. Technicians at animal facilities have stayed on, ensuring that the NIH's 1.4 million rodents and 3,900 non-human primates receive care. And several hundred employees are allowed to maintain irreplaceable cell lines.

Yet researchers are still finding themselves severely hobbled. One of the worst problems, some say, is the ban on ordering necessary lab materials such as enzymes and chemicals for culturing cells. "We can hold out for maybe a couple weeks with what we have, then we're in real trouble," says one lab head from the National Institute of Allergy and Infectious Diseases (NIAID). Like all of the NIH employees who spoke to Nature, he asked to remain anonymous because he is not authorized to talk to the media. Many experiments are being frozen - in some cases literally — as labs decide which can continue, which must be put on hold and which have to be abandoned. "If this goes on, whole experiments will begin to crumble," says the NIAID researcher.

With confusion reigning, the shutdown is playing out in different ways across the NIH's 27 institutes and centres. At the NIAID, for instance, lab heads have been instructed that they cannot have more than two people in a lab at any given time. Some institutes are allowing lab heads to recall workers as needed, whereas others have issued no clear directives. A few postdocs are ignoring the furlough, saying that they have had no specific orders to leave campus. One says that he and his colleagues have not been bothered yet, but he worries about being revealed if an accident occurs in the lab.

Lab heads, some of whom are themselves barred from campus, say that they have been told to write out precisely what each employee should be doing each day, and to justify each project. Mike Askenase, a graduate student at the University of Pennsylvania in Philadelphia who does research at the NIAID, is allowed 
- to work for just eight hours a week and only on experiments "that would cost more to shut down than to continue". He says his lab studies "mouse plague": Yersinia pseudotuberculosis, which in mice causes cysts and gut problems over the course of two to three months. The disease progression cannot be rescheduled, he says, and most researchers did not count on a shutdown when they started their experiments months ago. With just two people at a time in the lab, some parts of the experiments may go unfinished.

Researchers working on animals are among the most worried. One postdoc from the National Cancer Institute says that her security access was revoked at first, but after her adviser pleaded her case, she was given permission to enter her building for one hour per day to advise the technicians who are caring for her mice. The rodents were injected with cancerous cells several months ago, she says, and some of their tumours have now grown so large that the animals need to be killed. She is grateful for that one hour, she says, because it allows her to direct the technicians to take tissue biopsies so that she will be able to pick her experiment back up once the shutdown ends.

Other animal researchers say that the shutdown is affecting their projects in more unpredictable ways. One NIH scientist who works with primates says that it is keeping him from retrieving samples from the primate facilities in Poolesville, Maryland, 40 kilometres from Bethesda. Regulations require that animal-tissue specimens be transported in a government car, but the shutdown has kept government vehicles out of use. And if he cannot do his work, which involves human therapeutics, the researcher questions the morality of keeping the primates. "I don't think it's ethical to have an animal in a cage if we're not doing experiments on it," he says.

There is one place on campus that still seems to be doing good business: the small cafeteria in the NIH's Clinical Center. Normally used by patients, it is now the only place open to eat. The buzz of conversation there seems muffled. Discussions of science are overshadowed by doubt, worry and uncertainty.

\section{Modellers react to chemistry award}

\section{Prize proves that theorists can measure up to experimenters.}

\section{BY RICHARD VAN NOORDEN}

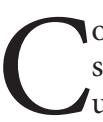
omputer modelling is one of the many scientific fields that Alfred Nobel, understandably, failed to anticipate in his 1895 will. And so, as Michael Levitt points out, "there's no Nobel prize for computer science”. But computation's increasing importance in chemistry and biology was recognized last week, when Levitt, of Stanford University in California, was one of three scientists to receive the chemistry Nobel for their work on ways to simulate the activity of large molecules - from cellular enzymes to light-absorbing dyes.

"Computers in biology have not been sufficiently appre-

ciated," Levitt said at a press conference, joking that a fourth portion of the Nobel might have gone to the chip manufacturers, who have driven up computing power exponentially.

Together with Martin Karplus of the University of Strasbourg in France and Harvard University in Cambridge, Massachusetts, and Arieh Warshel of the University of Southern California in Los Angeles, Levitt was honoured for a specific modelling technique: working out how to stitch together descriptions of molecules at close-up and zoomed-out scales.

The three were trailblazers in the 1970s. At the time, finely detailed quantummechanical pictures of bond making and breaking could not be calculated for more than a cluster of atoms - even today they are too complex to be computable beyond a few hundred atoms, and cannot be used to model whole proteins. So Levitt, Warshel and Karplus worked out how to merge these models with simplified simulations that treat molecules as non-reacting, vibrating atomic balls connected by springs. "The art is to find an approximation simple enough to be computable, but not so simple that you lose the useful detail," Levitt says.

These multi-scale models have proved essential for studying the workings of enzyme reactions, and were pioneered in a 1976 paper in which Warshel and Levitt explained how lysozyme cleaves a glycosidic bond. Multiscale techniques are not widely used in the drug industry, adds Kenneth Merz, who heads the Institute for Cyber-Enabled Research at Michigan State University in East Lansing. Instead, says theorist Christopher Cramer of the University of Minnesota in Minneapolis, they find uses in, for example, revealing how industrial catalysts work, or examining how light activates dyes on semiconducting nanoparticles.

The award is also being viewed as an acknowledgement of the three scientists' lifetime work in molecular simulation, researchers told Nature. "They have made theory an equal partner to experiment," said theoretical chemist Gunnar Karlström of Lund University in Sweden, a member of the Nobel committee.

Still, a question mark remains over whether theorists can make predictions that surprise experimenters. Computer modelling "is really good at helping people understand why things work the way they do, but not so good at predicting new things. We are good at guiding experimentalists," says Ken Houk, who uses computer programs to design new enzymes at the University of California, Los Angeles.

Experimenters should be cautious of simulation results, agrees Warshel. But "one day everything will be done by powerful computers", he predicts.

Cramer adds: "Every year, hazardous-waste disposal gets more expensive, whereas computing power gets cheaper. So the progress curves favour the theoreticians." -

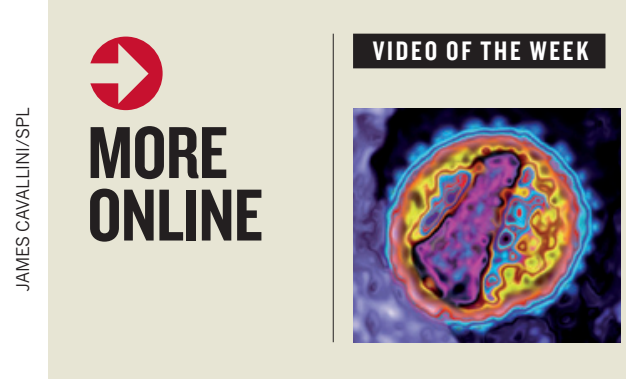

Mammals chop up viral RNA to attack infection go.nature.com/ sftmsh

\section{MORE NEWS}

- Quantum wavefunction collapse caught in slow motion go.nature.com/ ryu8ny

- Diamond drizzle forecast for Saturn and Jupiter go.nature.com/ripwmt

- Ozone loss warmed southern Africa go.nature.com/ph2nyo

\section{TOP STORY}

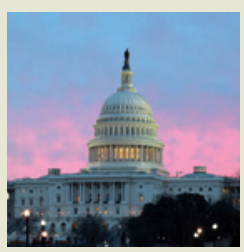

Live updates on how science is being hit by the US government shutdown go.nature.com/ u5kntz 